VARIA 


\title{
Líricos greco-romanos em Portugal: algumas traduções de Almeida Garrett e Antônio Feliciano de Castilho
}

\author{
Matheus Trevizam \\ Universidade Federal de Minas Gerais
}

\section{a) Introdução}

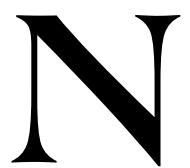

os últimos anos, o interesse dos acadêmicos, o espaço editorial $^{1}$ e (por que não?), o gosto do público, têm reabilitado o esforço de alguns poetas-tradutores. Herdeiros que somos de toda uma tradição romântica da "originalidade", ${ }^{2}$ ou, o que parece ainda mais delicado, do entendimento das obras "densas" como "espelhos" fiéis de seus autores, por muito tempo tendemos a negligenciar o trabalho

\footnotetext{
${ }^{1}$ Cf., por exemplo, reedições saídas há pouco da Eneida brasileira de Manuel Odorico Mendes (bem como revisão positiva de seu trabalho por vários estudiosos em nosso país) e dos excertos ovidianos das Metamorfoses por Bocage.

${ }^{2}$ de CAMPOS, 1992. p. 35 (citando Ezra Pound a respeito da reivindicação deste da condição criativa para o esforço tradutório bem direcionado): Uma grande época literária é talvez sempre uma grande época de traduções, ou a segue [...]. É bastante curioso que as Histórias da Literatura espanhola e italiana sempre tomem em consideração os tradutores. As histórias da Literatura inglesa sempre deixam de lado a tradução - suponho que seja um complexo de inferioridade - no entanto alguns dos melhores livros em inglês são traduções.

${ }^{3}$ Cf. nossas freqüentes tentativas de uso do texto literário como meio para "decifração" de faces "obscuras" da psicologia de seus autores: O poema "Caranguejola", de Mário, expressa com ironia a crise advinda da sensação de isolamento e do seu não reconhecimento como poeta, o que o impede de assumir uma postura mais independente e madura em seu meio(FERREIRA, 2006. p. 252).
} 
tradutório, mesmo quando oriundo das mãos de mestres da literatura luso-brasileira, como coisa menor, quase um exercício de desfastio em horas de pouca "inspiração".

Além dessas idéias a respeito do que seriam a "boa" arte e o "bom" artista em geral, parece-nos ainda contribuir para a específica desqualificação do intrincado processo tradutório a noção precária de que se trata de algo mais fácil, como se, havendo um caminho pronto a seguir (a letra do original em mira), bastasse trilhá-lo automaticamente com a troca das palavras e dizeres "alheios" pelos "próprios" e, assim, chegar sem percalços ao término da jornada.

Sem teorizar tecnicamente sobre o ato criativo de traduzir, fazemos, no entanto, atentar para fatos a desmentirem esses equívocos. Em primeiro lugar, já o ponto de partida, ou seja, os originais, costumam, quanto mais complexos e merecedores das atenções de todos, mostrarse refratários a leituras unívocas; de fato, em nossa experiência quotidiana de pesquisadores ou meros apreciadores de textos variados no vernáculo ou em línguas estrangeiras, com que freqüência não nos sentimos obrigados a reler, a buscar outras estratégias de acesso a hermetismos, a informar-nos mais, sem que por isso sempre houvesse garantia de escape ileso à incerteza! ${ }^{4}$

Ainda, a problemática colocada pela estética da recepção sequer nos permitiria mais crer ingenuamente nas chances de chegar a uma única resposta como ponto final de quaisquer leituras possíveis. ${ }^{5}$ Isso significa, além de fatores intrinsecamente vinculados à composição dos textos, que as próprias visões de mundo ou estruturas mentais dos leitores acabam por juntar-se ao conjunto de coordenadas atinentes à interpretação e

\footnotetext{
${ }^{4}$ Numa área como a filologia clássica, por exemplo, a "angústia" do leitor, ao lado das estruturas muito diferenciadas (e complexas) dos idiomas de escrita dos textos, de nosso efetivo afastamento cultural dos longínquos séculos da Antigüidade e da perda de importantes coordenadas de compreensão, é ainda acrescida pelos loci desperati de certas lições [VARRON, 2003. p. 40 (a propósito da completa impossibilidade de identificação geográfica da cidade ibérica de Oelies pelos eruditos)]. ${ }^{5}$ EAGLETON, 2003. p. 105: O leitor estabelece conexôes implicitas, preenche lacunas, faz deduções e comprova suposições - e tudo isso significa o uso de um conbecimento tácito do mundo em geral e das convençôes literárias em particular. O texto, em si, realmente não passa de uma série de "dicas" para o leitor, convites para que ele dê sentido a um trecho de linguagem.
} 
interferem de maneira decisiva no que cada qual pode oferecer como resposta no contato com as obras.

Quanto à parte em maior grau (mas não exclusivamente, como vimos) interpretativa do processo de traduzir, vale dizer, ao gesto de transcrever a alteridade para o domínio lingüístico do mesmo, há que se pensar no tema da parcial "incomunicabilidade" dos idiomas. Todo estudante de línguas estrangeiras, afoito por muito aprender em pouco tempo, não tarda a notar desconsoladamente que os modos de dizer, tão peculiares a cada idioma, não se identificam, por esse motivo, com simples seqüências fônicas diversas aplicadas às "mesmas" idéias. Então, a existência de duas palavras latinas bem distintas, patruus a aunculus, para designar o que abrangeríamos em português apenas com dizer "tio", termo aplicável entre nós indiferentemente aos parentes por linhagem paterna ou materna, indica ali a presença de um contraste conceitual ausente do vernáculo. Do ponto de vista cultural, assim, entendia-se que os filhos, coisas do pai em vida deste, deveriam, em sua morte, antes acatar o patruus (tio paterno e parente "mais próximo") do que o auunculus (tio materno), de fato preterido nessa relação. ${ }^{6}$

E, ao lado do problema vocabular e de diferente extensão semântica das "mesmas" palavras em distintos idiomas, há ainda questões morfossintáticas (caso típico das ricas flexões verbais e nominais nas línguas antigas) e sintáticas a demandarem a flexibilidade do tradutor para que se substitua o "faltante" na língua-meta pelo disponível...?

\footnotetext{
${ }^{6}$ VEYNE, 1993. p. 42: A morte do pai anunciava a herança dos filhos, exceto azar, e, em todo caso, ofim de uma espécie de escravidão; os filhos tornavamse adultos e a filha, se não fosse casada ou divorciada, tornava-se herdeira, livre para casar-se com quem bem quisesse (..). Ainda era preciso que a berdeira não caísse sob outra autoridade, a do tio paterno; esta severa figura procurará coibi-la de ter amantes secretos e a ocupará nos trabalhos forçados da roca e do fuso.

7 Resguardados contra as armadilhas da proposição da "superioridade" de quaisquer idiomas diante de outros, lembramos aqui o elevado juízo de Nietzsche a respeito da arte da poesia horaciana e a parcela do sucesso por ele atribuído a tal produção à natureza mesma da língua latina. De fato, considerando a grande liberdade posicional dos termos nas frases em latim e a relativa "concisão" sintética do idioma como pontos vantajosos aos artistas conscientes de seu potencial expressivo, a presença desigual desses traços na maioria das línguas modernas
} 
Por fim, como focalizamos aqui a tradução de textos literários, isto é, dotados de expressividade além do mero intento de "informar" com o uso dos mínimos recursos ditados pelas gramáticas de cada língua natural, importa também considerar a necessidade de interpretação com o sentido da busca de formas artísticas "paralelas". ${ }^{8}$ Como sabemos, essa etapa do fazer tradutório também se furta à obviedade em vista, por exemplo, das diferenças entre as tradições de escrita por vezes encontráveis no confronto das línguas e culturas postas em contato com a "passagem" textual de uma para outra.

Os poetas portugueses de que nos ocuparemos aqui, vale dizer, Antônio Feliciano de Castilho e Almeida Garrett, parecem-nos prestarse particularmente ao cotejo analítico no quesito de sua habilidade tradutória por terem sido ambos pertencentes ao mesmo período histórico-cultural do idioma luso (romantismo do século XIX) ${ }^{9}$ e, como

representa um importante desafio para os tradutores (NIETZSCHE, 1985. p. 136: Até hoje não senti com nenhum poeta aquele mesmo êxtase artístico que desde a primeira leitura me proporcionou a ode boraciana. O que aqui se alcançou é algo que, em certos idiomas, nem sequer se pode desejar. Esse mosaico de palavras, onde cada uma delas, como sonoridade, como posição, como conceito, derrama a sua força à direita e à esquerda e sobre o conjunto, esse "minimum" em extensão e em número de sinais, esse "maximum", conseguido desse modo, em energia dos signos - tudo isso é bem romano e se se me quiser crer, aristocrático "par excellence". ).

${ }^{8}$ de CAMPOS, 1992. p. 34: Admitida a tese da impossibilidade em princípio da tradução de textos criativos, parece-nos que esta engendra o corolário da possibilidade, também em princípio, da recriação desses textos. Teremos, como quer Bense, em outra língua uma outra informação estética, autônoma, mas ambas estarão ligadas entre si por uma relação de isomorfia: serão diferentes enquanto linguagem, mas, como corpos isomorfos, cristalizar-se-ão dentro de um mesmo sistema.

${ }^{9}$ O lisboeta Visconde Antônio Feliciano de Castilho (1800-1875), nascido com o século da decisiva consolidação burguesa contra o Antigo Regime, viveu o suficiente para polemizar com a nascente geração "realista" (liderada por Antero de Quental) na conhecida "Questão Coimbrã" (1864-1865); João Baptista da Silva Leitão de Almeida Garrett, por sua vez, antecedendo-o apenas um ano ao nascer, faleceu em 1854. 
bons classicistas, ${ }^{10}$ em mais de uma ocasião porta-vozes de musas antigas em nossa língua. Dessa maneira, em conformidade com as idéias aludidas até aqui, esforçar-nos-emos em seguida por focalizá-los, a propósito de uma única ode anacreôntica e de dois poemas do lírico romano Gaio Valério Catulo (séc. I a.C.), em sua face de intérpretes a contribuírem criativamente para a feitura de novos poemas portugueses em diálogo com suas "matrizes" greco-latinas.

As boas chances de rendimento de uma análise tradutória a leválos em conta vinculam-se, assim, ao fato de que a proximidade (ou mesmo a exata coincidência, no caso do modelo grego repercutido) de suas fontes de trabalho, bem como a ausência de discrepâncias abruptas quanto ao material lingüístico de que se servem em um e outro caso para (re)criar, tornam as eventuais diferenças nos textos obtidos claros indícios de opções artísticas idiossincraticamente condicionadas. E os diferentes reflexos a produzirem-se assim na escrita de cada um dos poetas têm muito a dizer não só sobre sua sensibilidade mas, ainda, sobre o alcance do espectro expressivo de nossa língua naquele momento dado.

\section{b) Cotejo das traduções anacreônticas}

A ode "À cítara", imprecisamente ${ }^{11}$ atribuída a Anacreonte de Teos (séc. VI-V a.C.), apresenta, no original grego, grande limpidez compositiva:

\footnotetext{
${ }^{10}$ A instrução no conhecimento dos clássicos, sobretudo latinos, constituiu, não há como negar, a base do ensino formal no ocidente por séculos a fio. Assim, sobre Castilho, vemo-lo desde a infância dedicado ao aprendizado do latim na escola de mestre José Peixoto do Valle e, logo, ao da retórica pelas mãos de Maximiano Ribeiro (FERREIRA, 1971. p. 104). São, em seguida, mais conhecidas suas realizações como convicto tradutor dos clássicos, sobretudo romanos (Cícero, Virgílio, Ovídio, Catulo, Juvenal, Pérsio...). Almeida Garrett, por outro lado, tendo recebido de um tio paterno, clérigo na Ilha Terceira dos Açores, alguma instrução greco-latina, deu a público sua primeira obra entremeada de assuntos míticos com o nome de O retrato de Vênus e logo fez encenar (1821) uma peça inspirada na personagem do político romano Catão Uticense (COELHO, 1917. p. 122ss.).

${ }^{11}$ Cf. prefácio de Almeida Cousin à sua tradução portuguesa dessas Odes: Anacreonte-o das odes que correm o mundo- não é mais do que uma atitude de espírito grego, e a atitude, já, dos séculos da decadência. (...) Certamente as "Odes Anacreônticas" que conbecemos não pertencem a um autor exclusivo,
} 
ela se identifica, em breve desenvolvimento do topos da recusatio, com imputar a instrumentos musicais a responsabilidade por não se compor na clave heróica. Diversamente do que se notava em outros contextos de emprego desse lugar-comum, ${ }^{12}$ pois, trata-se não de apresentar às claras a "incapacidade" do poeta, a quem faltaria o ingenium necessário para elevar-se de âmbitos expressivos modestos a gêneros mais imponentes, mas, mitigando em parte a própria participação nesse "fracasso", de desviar as atenções do público para a "teimosia" das cordas.

Ao bom leitor, no entanto, não passaria despercebido que a insistência anacreôntica em manter-se fiel à lírica amorosa parte no fundo de uma obstinada adesão do "eu-lírico" a formas expressivas apenas em superfície dadas como "baixas" demais: apesar da troca das cordas e da própria $\beta \alpha / \rho \beta \imath \tau o \varphi$ antiga, com efeito, observamos, a partir do quinto verso, a produção em idêntico registro poético também no novo. Em outras palavras, o "eu-lírico", evitando rejeitar agressivamente ou em aberto desinteresse cantos tão prestigiados na tradição antiga, prefere realizar sua recusa exprimindo intentos muito epidérmicos de vincular-

porém a vários, e têm características, não dos tempos severos e religiosos que antecederam as guerras Pérsicas, porém as daqueles em que se diluía a Grécia, misturando-se com o Oriente, na expansão e desmembramento do Império de Alexandre. São, pois, na sua maioria ou quase totalidade, obra de imitadores joviais e discípulos graciosos, que viveram até cerca de três séculos, senão mais, depois da morte do poeta a quem são atribuidas (ANAKREONTOS, 1983. p. 9).

12 TIBULO I, I 53-56: Te bellare decet terra, Messalla, marique,/ ut domus hostiles praeferat exuuias:/ me retinent uinctum formosae uincla puellae,/ et sedeo duras ianitor ante fores - "Convém que tu guerreies, Messala, na terra e no mar/ para que tua casa ostente despojos inimigos:/ a mim, prendem os laços de uma menina formosa,/ e me disponho a porteiro diante de portas cruéis" (minha tradução). Na elegia erótica romana, de que esse autor é um dos representantes, caminho de vida e caminho de poesia se fundem numa só coisa; desse modo, enleados por uma paixão avassaladora, os poetas-amantes nada mais fazem a não ser devotar-se a ela servindo à puella ou compondo elegias a patentearem seu amor. Isso significa que, recusando-se a guerrear como Messala para entregar-se todo a Délia, "Tibulo" (a imagem do eu-lírico tal qual presentificada no poema) também desiste de compor outro tipo de poesia (épica, por exemplo) por não poder libertar-se dos laços que o "amarram". 
se a eles e, ainda, fazendo "crer" aos ingênuos que de fato seria coagido por fatores externos a manter-se como está. ${ }^{13}$

Parece-nos, assim, que nos é proposta nas entrelinhas do poema a valorização da musa lírica em sutil detrimento da épica (ou trágica?). ${ }^{14}$ Essa constatação, aliada ainda a certos indícios bem concretos do texto (como a "despedida" final dos heróis), permitir-nos-ia aventar um tom bem humorado e, por que não, mesmo irônico como marca geral da ode em vista. ${ }^{15}$ Pois, diante do óbvio talento do autor em exprimir-se com graça na clave supostamente preterida e em rechaçar de leve domínios compositivos nos quais não se sente tão à vontade, presentifica-se certo teor de auto-satisfação.

Formalmente, os versos gregos de base rítmica jâmbica prescindem de todo de rimas: trata-se, por sinal, de um recurso generalizado no ocidente apenas a partir dos hinos litúrgicos da Idade Média. ${ }^{16}$ Além disso, invariavelmente compostos de sete sílabas poéticas, recorrem modestamente a alguns recursos expressivos como a anástrofe $(\theta \varepsilon / \lambda \omega / \theta \varepsilon /$

${ }^{13}$ Semelhante atitude parece manifestar-se no início da primeira elegia dos Amores de Ovídio, na qual o "culpado" pelo impedimento da composição épica é Cupido: Arma graui numero uiolentaque bella parabam/ edere, materia conueniente modis./ Par erat inferior uersus; risisse Cupido/ dicitur atque unum surripuisse pedem. - "Ia armas e guerras violentas em ritmo grave/ mostrar, matéria conveniente à medida./ Par era o verso inferior; mas diz-se que Cupido/ riu e roubou um pé" (minha tradução). De fato, o verso épico, do começo ao fim das principais epopéias antigas, restringia-se ao hexâmetro datílico, em contraste com os dísticos elegíacos (o metro da elegia erótica romana e, portanto, dos próprios Amores a começarem daqui) a combinarem-no com os pentâmetros, de menor extensão.

${ }^{14}$ Uma personagem heróica como Hércules, por exemplo, embora não tenha protagonizado na galeria de personagens da épica antiga, furtava-se decerto ao comum dos mortais (era um semi-deus) e foi tema de duas tragédias senequianas (Hercules furens e Hercules Oetaeus).

${ }^{15}$ Remetemos novamente o leitor à elegia ovidiana citada, em que não falta, sequer, o sugestivo emprego do verbo risisse em v. 3.

${ }^{16}$ MOISÉS, 2004. p. 435: Em todas essas manifestações é lícito divisar o embrião da rima: sua gênese estava nos hinos cristãos dos primeiros séculos. (...) Assim, no século $X$ dá-se o aparecimento da rima como a entendemos hoje, a qual alcançaria, nas duas centúrias seguintes, o apogeu de sua perfeição. 
$\lambda \omega)$, o quiasmo $(\lambda \varepsilon / \gamma \varepsilon \imath v) \mathrm{A} \tau \rho \varepsilon / / \delta \alpha \varphi / \mathrm{K} \alpha / \delta \mu \mathrm{ov} \#) / \delta \varepsilon \imath v)$, a repetição $(\lambda v /$ $\rho \eta v / \lambda v / \rho \eta / \lambda v / \rho \eta)$ e o posicionamento fônico expressivo de três verbos conjugados a partir do quarto verso $(\eta) \xi \varepsilon l=/ \alpha) \nu \tau \varepsilon \phi \omega / v \varepsilon l \varepsilon \#) / \delta \varepsilon 1$, sempre em término das linhas).

Transcrevemo-los abaixo em tradução literal, bem como as correspondentes traduções de Castilho e Garrett:

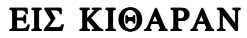

$\Theta \varepsilon / \lambda \omega \lambda \varepsilon / \gamma \varepsilon i v) \mathrm{A} \tau \rho \varepsilon \mathrm{l} / \delta \alpha \varphi$,

$\Theta \varepsilon / \lambda \omega \delta \varepsilon \therefore \mathrm{K} \alpha / \delta \mu \mathrm{ov} \#) / \delta \varepsilon i v:$

)$=\mathrm{A} \beta \alpha / \rho \beta \mathrm{\tau} \tau \mathrm{O} \varphi \delta \varepsilon \therefore \xi_{\mathrm{O}} \rho \delta \alpha \mathrm{l}=\varphi$

)$/ E \rho \omega \tau \alpha \mu \mathrm{ov}=v o v \eta) \xi \varepsilon l=$.

)$/ \mathrm{H} \mu \varepsilon \mathrm{\psi} \psi \alpha \nu \varepsilon v=\rho \alpha \pi \rho \omega / \eta \nu$,

$K \alpha 1 \therefore \tau \eta \therefore v \lambda v / \rho \eta v \alpha(/ \pi \alpha \sigma \alpha v$,

$\mathrm{K} \alpha) \gamma(\omega \mu \mu \therefore \vee \exists=) \delta \circ \nu \alpha) / \theta \lambda \circ \vee \varphi$

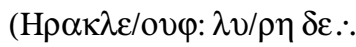

)$/ E \rho \omega \tau \alpha \varphi \alpha) \nu \tau \varepsilon \phi \omega / v \varepsilon 1$.

$\Xi \alpha \mathrm{l} / \rho \circ \tau \varepsilon \lambda \mathrm{ol} \pi \mathrm{o} \therefore \nu \eta(\mu \mathrm{l}=v$,

(/Н $\rho \omega \varepsilon \varphi: \eta(\lambda v / \rho \eta \gamma \alpha \therefore \rho$

$\mathrm{Mo} / \operatorname{vov\varphi }) / \mathrm{E} \rho \omega \tau \alpha \varphi \#) / \delta \varepsilon .^{17}$

\section{Versão de Castilho}

De Atridas os feitos, de Cadmo os louvores

Tentei celebrar;

E a lira rebelde só cantos de amores

Me quis entoar.

Impus-lhe outras cordas... Trabalho perdido!

A lira troquei;

Aos feitos de Alcides a nova convido...

\section{À cítara}

Quero falar dos Atridas, Quero Cadmo celebrar, O bárbito com as cordas Ressoa apenas o Amor. Troquei as cordas há pouco, Bem como a lira inteira, E eu cantava trabalhos De Héracles: mas a lira Respondia com Amores. De resto, dai-nos adeus, Ó Heróis: pois a lira Apenas Amores canta. ${ }^{18}$

\section{Versão de Garrett}

De gosto cantara Atridas, E a Cadmo erguera louvor; Porém as cordas da lira Só sabem dizer amor. Há pouco, mudando-a toda, Novas cordas lhe assentava, E de Alcides os trabalhos

\footnotetext{
${ }^{17}$ ANAKPEONTOE, 1983. p. 20.

${ }^{18}$ Minha tradução literal (agradeço, porém, aos helenistas Teodoro Rennó Assunção e Antônio Orlando Dourado Lopes pelo atencioso auxílio com as dificuldades do texto grego).
} 
E "Amor" lhe escutei!

Adeus, grandes homens! Buscai noutra lira

O vosso louvor!

A minha não sabe; não pode; suspira

Só cantos de amor. ${ }^{19}$
A cantar principiava;

Mas, contra as minha tenções

Em vez de marciais furores,

De teimosa e como a acinte,

Sempre vai soando amores.

Adeus, heróis! Adeus, glória!

Adeus, guerreiro furor!

As cordas da minha lira

Só sabem dizer amor. ${ }^{20}$

Ora, Castilho, curiosamente, variando muito os metros, de uma maneira ausente no original, esgotou a construção de sua ode com seis dísticos a aludirem aos doze versos gregos. Além disso, ao incluir sistematicamente a rima como parte do arsenal de recursos artísticos utilizados em português, vemos que se sucedem segundo o esquema abab-cdcd-efef, de modo a favorecer-se, apesar da ausência de divisões espaciais, como que a criação de "estrofes". Também nesse ponto o tradutor se mostra atento à forma do original, pois, embora não houvesse ali a mesma simetria de estrutura (com uma primeira "seção" de quatro versos, uma penúltima de cinco e uma última de apenas três), notávamos a divisão do todo em três blocos formados pela delimitação recíproca de sentidos.

Para os leitores mais próximos dos clássicos, por outro lado, não passaria despercebida a associação entre a temática amorosa e a escrita de dísticos elegíacos. ${ }^{21}$ Embora, é evidente, a opção métrica de Anacreonte não seja essa, sugerimos que Castilho, habituado que estava com a forma, pode ter-se lembrado dela a propósito de um texto com esses sentidos e ao menos aludido à sua existência.

Ainda, sobre os aspectos formais mais ostensivos do poema português no cotejo com o grego, parece importante fazer atentar para os efeitos da alternância de um metro longo (o dos hendecassílabos) e um breve (o dos pentâmetros), com resultado de "desafogo" rítmico e leveza

\footnotetext{
${ }^{19}$ COELHO, 1917. p. 62-63.

${ }^{20}$ COELHO, 1917. p. 62.

${ }^{21}$ Cf. supra nota 13.
} 
garantidos pelo menor, ademais, popular em nossa língua. ${ }^{22}$ Conseguese, assim, a quebra da solenidade ${ }^{23}$ (algo de todo ausente do original anacreôntico com sua fuga à poesia "séria") e a construção de um conjunto em delicado equilíbrio. Por fim, embora jamais tivesse havido rimas no texto grego, o posicionamento em "fecho" dos verbos $\eta) \xi \varepsilon l=, \alpha) v \tau \varepsilon \phi \omega /$

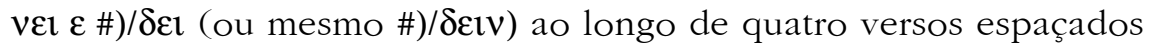
contribuía, de modo que não julgamos, em absoluto, insipiente, para conferir sons peculiares à ode.

Do ponto de vista da recuperação estrita dos sentidos, são feitas, como seria esperado, pequenas modificações. A título de exemplificação, pois, em vez de duas expressões introduzidas por infinitivos diferentes como objetos do verbo $\theta \varepsilon / \lambda \omega$ reiterado em v. 1 e 2 , Castilho empregou uma única vez "tentei" com "celebrar", de certo modo apagando nuanças sintáticas do original. E poder-se-iam citar como acréscimos "rebelde" (v. 3), "cantos" (v. 3) e "trabalho perdido" (v. 5), bem como o desdobramento de uma estrutura grega mais simples $(\eta) / \mu \varepsilon \imath \psi \alpha v \varepsilon v=\rho \alpha \pi \rho \omega / \eta v, / \kappa \alpha \iota . \therefore$

${ }^{22}$ MOISÉS, 2004. p. 511.

${ }^{23}$ Os versos mais longos em português, sobretudo o decassílabo, celebrizado por Camões n 'Os Lusíadas, e o alexandrino (ou dodecassílabo, metro advindo da tradição francesa), revestem-se da dignidade ou de outros atributos necessários para a escrita de formas eruditas como a épica, os sonetos ou a poesia bucólica. Cf., a esse respeito, as palavras seguintes de Raimundo Carvalho sobre suas opções formais para traduzir em versos as Bucólicas virgilianas (VIRGÍlLIO, 2005 a. p. 109): Com essa exposição, pretendo explicitar ainda mais os princípios que nortearam a minha atividade tradutora que, partindo de Valéry, não se esgota nele. Na verdade, mantenho com seus escritos uma relação dialógica de aproximação e recusa. Como exemplo de aproximação, cito a escolba do verso alexandrino clássico para traduzir o bexâmetro datílico. Aquele, tanto em francês como em português, é um verso que, pela sua extensão, permite ao tradutor dar conta do original, fazendo corresponder, verso a verso, original e tradução; ou seja, para cada bexâmetro um alexandrino. Deve ficar claro, também, que a escolba do alexandrino clássico para a minha tradução não se justifica apenas por espelhamento com a de Valéry. Quis que- numa série em que já existem duas traduções brasileiras em verso das "Bucólicas", uma em decassílabos, a de Odorico Mendes; outra em alexandrino arcaico (de catorze silabas), a de Silva Ramos - a minha ocupasse uma brecha entre a extrema concisão do mestre oitocentista e a quase prosa do outro. 
$\tau \eta \therefore v \lambda v / \rho \eta v \alpha(/ \pi \alpha \sigma \alpha v$, v. 5 e 6$)$ para indicar a troca das cordas ou da lira inteira ("impus-lhe outras cordas.../ a lira troquei, v. 5 e 6); em seguida, trocou-se "Héracles" (v. 8) por "Alcides"24 (v. 7) e o sujeito e o sentido do verbo correspondente no v. 9 do original ("e Amor lhe escutei" por $\varepsilon) / \rho \omega \tau \alpha \varphi \alpha) v \tau \varepsilon \phi \omega / v \varepsilon l$ ), o mesmo, quanto ao último ponto, podendose dizer de "grandes homens" (por "heróis") em v. 9. Por fim, são livres criações "o vosso louvor" e, definitivamente, "não sabe, não pode".

$\mathrm{Na}$ versão garretiana, por sua vez, escolheram-se redondilhas maiores para corresponder à forma do poema do início ao fim; com isso, é evidente, o tradutor português se aproxima do original pela manutenção de um único tipo métrico de mesma quantia silábica da ode grega (embora característico da tradição ibérica) ${ }^{25}$ em contraste com a maior liberdade criativa de Castilho.

Distanciando-se, por outro lado, do original grego em aspectos vinculados à rima (primeiro, por sua existência mesma na versão oitocentista), Garrett delimita claramente quatro "estrofes" simétricas no texto, em contraste com as três seções assimétricas do original (abcb-defeghih-jbcb). Visualmente, entretanto, exceto o destaque dado no recuo ao primeiro verso de cada "estrofe", fica-se mais próximo da apresentação distributiva do modelo, e o fato de não se rimarem todos os versos harmoniza, guardadas as devidas proporções, a versão garretiana com o recurso de mera reiteração fônica dispersa, visto antes a propósito de alguns verbos gregos em posição terminal.

Como tentativa de "transmitir" os significados da ode anacreôntica em pauta, esta versão nos parece, no cotejo com a de Castilho, algo mais "pesada", no sentido de afeita a certos desenvolvimentos desnecessariamente afastados da imediatez do poeta helênico. Assim, contribuem de início para esse efeito os usos do lusitanismo "de gosto" (v. 1) em lugar do comuníssimo verbo grego $\theta \varepsilon / \lambda \omega$ e da pomposa expressão "erguera louvor" (v. 2) pelo infinitivo \#)/dein, posto como objeto do mesmo verbo. Em seguida, contrastando com a grande fluidez e concisão (re)criadora

${ }^{24}$ SPALDING, 1965. p. 11: Alcides, nome patronímico que designa Hércules, neto de Alceu.

${ }^{25}$ GOLDSTEIN, 1986. p. 27: O verso de sete silabas, heptassílabo ou redondilha maior, é o mais simples, do ponto de vista das leis métricas. (...) Talvez por isso ele seja o verso predominante nas quadrinhas e canções populares. Verso tradicional em lingua portuguesa, já era freqüente nas cantigas medievais. 
da segunda "estrofe" (descontado, no segundo quesito, a troca de "Héracles" pelo "volteio" erudito do epíteto correspondente - v. 7), vemos manifestar-se na terceira acréscimos e desvios decerto motivados apenas pelo intento de manter-se fiel à forma eleita desde o começo, mesmo quando se aproxima o final do poema... e começam a faltar os conteúdos necessários. Isso justifica a presença de quatro versos (9-12) em lugar das meras quatro palavras gregas utilizadas por Anacreonte em 8-9 ( $\lambda v / \rho \eta \delta \varepsilon /$ $\varepsilon) / \rho \omega \tau \alpha \varphi \alpha) v \tau \varepsilon \phi \omega / v \varepsilon \imath$ ); neles, ainda, acumulam-se dizeres pouco espontâneos para nossos ouvidos, caso de "marciais furores" e de tudo o que se encontra no décimo verso ("de teimosa e como a acinte"). Ainda, antes de encerrar o poema com dois versos de elegante simplicidade, Garrett recorre, pela mesma "coerção" vista há pouco, ao excesso de reiterar três vezes "adeus" (e a diferentes "destinatários"!), em tentativa de

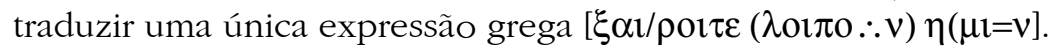

O tom de nosso comentário deve ter bastado para fazer ver por que julgamos a versão de Castilho mais bem realizada do ponto de vista artístico e, por assim dizer, mais "moderna" lingüisticamente do que a de Garrett, apesar da relativa proximidade semântica de ambas diante do modelo e dos invariáveis intentos de atualizar a forma. ${ }^{26} \mathrm{E}$, a levarem-se em conta nossas palavras iniciais sobre a necessidade de valorização do bom poeta-tradutor, avantaja-se aqui o veio poético de Castilho.

Por fim, em breve retomada de pontos discutidos antes, propomos que se considere a variação dos nomes dos instrumentos musicais citados por Anacreonte como exemplo de dificuldade interpretativa no original:

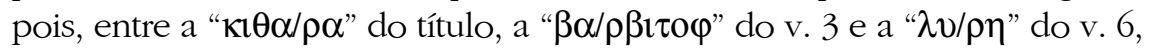
ter-se-ia desejado indicar que não há diferenças substanciais a ponto de serem as três palavras tomadas como sinônimos? E, nesse caso, por que, enfim, variar tanto as formas lingüísticas para indicar o "mesmo"? ${ }^{27}$

${ }^{26}$ Cf., além do recurso métrico em Garrett e da tentativa comum de reiterar fonicamente elementos variados do grego, a semelhança em Castilho de "de Atridas"/ "de Cadmo" com a anástrofe constituída por $\theta \varepsilon / \lambda \omega$ e a "manutenção" do quiasmo citado antes (p. 6) com dizer o outro poeta "cantara Atridas"/ "a Cadmo erguera louvores".

${ }^{27}$ HORNBLOWER; SPAWFORTH, 2003. p. 104: Bowl-lyres are principally represented in Greece by the lyra proper ( $\lambda v / \rho \eta$ o $\rho \varepsilon / \lambda v \varphi)$. Its soundbox was a tortoiseshell, or perhaps sometimes wood, shaped and painted to resemble one. A thin sheet of hide fixed across the opening formed the face and supported the bridge. 
A especificidade semântica da palavra grega $\varepsilon) / \rho \omega \varphi$, por outro lado, contribui de maneira decisiva para conferir ao poema, espécie de "porta" de entrada ${ }^{28}$ para a antologia anacreôntica, o tom de incitamento à fruição dos prazeres dos sentidos (quer provenham do amor, quer do vinho ${ }^{29}$ a perpassá-la freqüente. Pois, não há que se esquecer, $\left.\varepsilon\right) / \rho \omega \varphi$, segundo outra célebre passagem da lírica helênica antiga, é força concreta a subjugar o corpo do apaixonado, sem abstratas conotações de uma inquietude da "alma". 30

\section{c) Cotejo das traduções dos carmina de Catulo}

Poeta, dentre os líricos latinos, indubitavelmente privilegiado pelos tradutores de nossa língua (notem-se, além das traduções parciais de Garrett e Castilho, as de Péricles Eugênio da Silva Ramos, José Paulo Paes, Haroldo de Campos e João Angelo Oliva Neto), ${ }^{31}$ Catulo será representado neste comentário pelos poemas de número 5 e 85 . Trata-se, para os apreciadores da musa romana, de peças-chave no panorama do autor por,

The arms were sticks curved like horns (...). A variant, the "barbitos" appeared during the $\sigma^{\text {th }}$. cent. B.C. and was common in the $5^{\text {th }}$., differing only in its longer differently shaped arms. (...) Late in the $7^{\text {th }}$. cent. B.C., apparently after a period of experimentation, the great "kithara" that became the major instrument of professional and public performance first appears in art. The base of the much enlarged box is flat, the straight sides angled outwards: the back bulges along its vertical axis.

${ }^{28}$ Ao menos, na edição aqui adotada.

${ }^{29}$ EASTERLING; KNOX, 1988. p. 216: Most of his poetry was concerned with love and wine. Maximus of Tyre (37.5) summed up its content as "the hair of Smerdies and Cleobulus, the pipe of Bathyllus and Ionian song"; but Cicero ("Tusc. Disp." 4.71) exaggerates when he says it was all erotic.

${ }^{30}$ Cf. fragmento 18 de Safo de Lesbos, na tradução de Joaquim B. Fontes Jr.

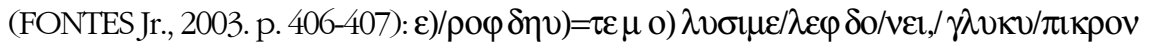

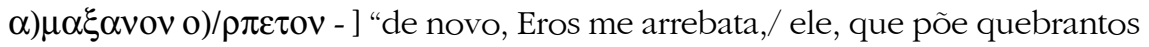
no corpo,/ dociamaro, invencível serpente".

${ }^{31}$ Cf. antologia de traduções catulianas compiladas por João A. Oliva Neto no final do volume que organizou para o espólio do poeta (CATULO, 1996. p. 163-180). 
de alguma maneira, presentificarem agudamente a força do sentimento amoroso.

Em 5, com efeito, vemo-lo envolvido com a personagem de Lésbia, figura ideal da amante ao longo de vários de seus 116 poemas. ${ }^{32} \mathrm{Em}$ contraste com o texto de Anacreonte visto acima, não há aqui a dispersão do foco para pontos diversos da ênfase na temática amorosa em si mesma compreendida (por um "atalho" metapoético, como vimos), mas sim a efetiva insistência na necessidade de fruição da vida: ocorre que, sendo a felicidade possível e ameaçando-os as sombras da inveja, da censura e, sobretudo, da morte, logo se recomenda aos apaixonados a plena entrega mútua. ${ }^{33}$

Tal "aviso" à amada se faz, sobretudo na parte final do poema, de uma maneira afim à linguagem da contabilização financeira: ocorre, além da explícita menção à unidade monetária de valor irrisório em v. 3, que o fecho do texto, na verdade identificado com uma sucessão de cifras que se deseja avidamente somar e resguardar das más influências de estranhos, pode ser entendido como incitamento à feitura conjunta de uma sólida "fortuna". E o resguardo do vultoso número de beijos dos olhos e ouvidos de estranhos vincula-se, assim, à necessária cautela de todos os possuidores de bens reputados significativos diante das ameaças representadas pelo excessivo contato dos "profanos" com tudo aquilo que lhes diga respeito, da forma exata que se dá com os valores monetários.

Eis abaixo o original latino, sua tradução literal e a versão poética garretiana:

${ }^{32}$ FEDELI, 1990. p. 90-91: In merito alla Lesbia catulliana sembrano oggi sopite le controversie che da sempre hanno travagliato la critica e regna um accordo pressoché totale in favore dell'identificazione, antica quanto Pier Vettori, con la "Clodia Metelli" (e dunque con la seconda delle tre sorelle di Clodio, moglie di Quinto Cecilio Metello Celere, che, console nel 60, mori l'anno dopo).

${ }^{33}$ Segundo observação de Achcar, vemo-nos, diante desse poema, apreciando variantes do topos do carpe diem [ou do spernere uulgus, "desprezo (altivo) ao vulgo"]: ACHCAR, 1994. p. 76. 
Viuamus, mea Lesbia, atque amemus, rumoresque senum seueriorum omnes unius aestimemus assis. Soles occidere et redire possunt; nobis cum semel occidit breuis lux, nox est perpetua una dormienda. Da mi basia mille, deinde centum, deinde usque altera, dein secunda centum, deinde usque altera mille, deinde centum. Dein, cum milia multa fecerimus, conturbabimus illa, ne sciamus, aut ne quis malus inuidere possit, cum tantum sciat esse basiorum..$^{34}$
Vivamos, minha Lésbia, e amemos, e os rumores de velhos bem severos estimemos todos de um vintém. Os sóis podem morrer e renascer; nós, quando nos morre a breve luz, uma só noite eterna dormiremos. Dá-me mil beijos, depois cem, logo depois outros, depois mais cem, logo depois outros mil, depois cem. Depois, dados muitos milhares, confundiremos para não saber, nem maldoso algum possa invejar, sabendo que há tantos beijos. ${ }^{35}$

\section{Versão de Garrett}

Vivamos, minha Lésbia, amemos sempre, E os rumores dos velhos rabugentos

Saibamos desprezar, tê-los em nada.

O sol pode morrer, tornar de novo;

Nós, se uma vez a breve luz nos morre, Uma e perpétua noite dormiremos.

Oh! mil beijos me dá, depois um cento, E mil outros depois, mais outro cento, E outros mil, e outros cem; e quando ao cabo Muitos milhares ajuntarmos deles, Em maga confusão juntá-los-emos, Que não saibamos nós, que ninguém saiba, Nem maldoso algum possa invejar-nos, Se de tantos souber, tão doces beijos. ${ }^{36}$

A tradução garretiana, adaptando a dicção latina ao português com alguma liberdade (caso da introdução de "sempre" em v. 1, do apagamento da referência "monetária" em v. 3, do emprego do lusitanismo "ao cabo" em v. 9, do uso interpretativo de "em maga confusão" em v. 11 e "doces"

\footnotetext{
${ }^{34}$ CATULO, 1996. p. 71.

${ }^{35}$ Minha tradução literal.

${ }^{36}$ CATULO, 1996. p. 164.
} 
em v. 14), sustenta-se como obra (re)criadora justamente por livrar-se do servilismo à matriz ecoada. Assim, em v. 2, consideramos ainda contribuir para a integração da poética catuliana ao universo literário luso o expressivo uso do termo "rabujentos" pelo comparativo latino seueriorum ("um tanto severos"), ${ }^{37}$ o mesmo podendo-se dizer da interjeição "oh!" em v. 7, como que a ressaltar a sofreguidão emocional pela soma imediata de beijos.

Do ponto de vista formal, os quatorze versos de Garrett pelos treze do original latino e seus decassílabos pelos hendecassílabos falécios ${ }^{38}$ naquele contexto contribuem para uma relativa proximidade mútua de medida. Além disso, as marcadas aliterações catulianas em "m" nos três primeiros versos (com dez ocorrências) encontram ecos aproximativos nas mãos atentas de Garrett, já que, para escrever a passagem correspondente em seu texto, recorreu ao todo a doze sons nasais, entre efetivos empregos da consoante aludida, de "n", de "nh" ou de meras nasalizações de vogais circunvizinhas. Por outro lado, ecoando quatro palavras imediatamente "aparentadas" às latinas em v. 6 ("uma e perpétua noite dormiremos"), ele retoma a musicalidade do verso catuliano em mira não só pela repetição das quatro nasais ali presentes, mas ainda por reiterar a "longa", enfática e "monótona" palavra "perpétua". Por fim, as repetições finais de cifras ou outras expressões enfatizadas no latim (caso de "e" em v. 8 e 9 pelo deinde de Catulo) afinam a "tessitura" do poema português com um traço essencial à forma e aos sentidos do romano.

No todo, portanto, resulta a impressão de uma (re)criação fluida e bem "aclimatada" ao momento criativo em que se inseriu Garrett, podendo-se dizê-lo, talvez, mais feliz ao traduzir Catulo do que a ode comentada antes...

O poema 85 de Catulo, por sua vez, na verdade um brevíssimo epigrama ${ }^{39}$ identificado com apenas um dístico elegíaco, recebeu de Castilho um tratamento muito específico:

\footnotetext{
${ }^{37}$ Parece oportuno, aqui, que a expressão escolhida por Garrett seja sintética e, ainda assim, capaz de responder à altura da intensidade do "comparativo" enfático em latim (severiorum, "dos um tanto severos", "dos bem severos").

${ }^{38}$ CATULO, 1996. p. 185.

${ }^{39}$ CITRONI, 1991. p. 171: Una ricotruzione storico-evolutiva della produzione epigrammatica presenta gravi difficoltà, per diverse ragioni. In primo luogo, non si possono fissare com nettezza i limiti del genere. (...) D'altra parte,
} 
Odi et amo. Quare id faciam, fortasse requiris.

Nescio, sed fieri sentio et excrucior. ${ }^{40}$

Odeio e amo. Por que faço isso talvez perguntes.

Não sei, mas sinto acontecer e me torturo. ${ }^{41}$

Versão de Castilho

Odeio e amo ao mesmo tempo.

Como pode ser? (perguntas)

Duas coisas tão opostas

Ao mesmo tempo tão juntas?

Como pode ser ignoro;

Sei que o sinto, a causa és tu,

E sei que é tão cru o tormento,

Que o não pode haver mais cru. ${ }^{42}$

Diversamente da ode anacreôntica traduzida por ele mesmo e do poema catuliano de número cinco, tal qual "trasladado" por Garrett, o tradutor recorreu aqui ao original apenas como meio básico para desenvolver sua própria criação: pois, diante do desdobramento de dois versos iniciais em duas estrofes respectivas, há que se mencionar a presença de demasiada liberdade poética para que se pudesse pensar em

estendere, come pare necessario, il concetto di epigramma a ogni tipo di carme breve di carattere occasionale, personale, satirico, morale, comporta uma malcerta delimitazione rispetto alle tradizioni della poesia giambica e della poesia lirica (come è chiaro soprattutto nel caso di Catullo). La terminologia usata dagli antichi non è, del resto, univoca: Marziale chiamma regolarmente "epigrammata" i suoi componimenti di carattere vario e di vario metro, ma prima di Marziale e ancora al suo tempo erano usate, per poesie del genere, anche altre denominazioni, che facevano riferimento al metro (ad. es. "bendecasyllabi") o al carattere "minore" (ad. es. "nugae", "poematia", "idyllia"): significativo in proposito Plin. "Epist." IV 14, 9.

${ }^{40}$ CATULO, 1996. p. 150.

${ }^{41}$ Minha tradução literal.

${ }^{42}$ CATULO, 1996. p. 177. 
"transcriação". ${ }^{43}$ De fato, diante de expressões altamente interpretativas como "ao mesmo tempo", "duas coisas tão opostas/ ao mesmo tempo tão juntas", "a causa és tu" e "que o não pode haver (mais cru)", seria o caso de nos perguntarmos pelo próprio "paradeiro" do poema catuliano. Mesmo as partes destinadas a traduzir com maior "fidelidade" o original (caso de "como pode ser ignoro" por nescio e "sei que o sinto" por fieri sentio), por outro lado, não prescindem de todo de acréscimos, patenteando-se assim a nós o por quê de tão significativo aumento do tamanho do texto.

Com esse efeito, notamos, desfaz-se a tônica expressiva do epigrama latino, ${ }^{44}$ caracterizada pela dura antítese dos sentimentos em jogo e por um eloqüente laconismo em face da incompreensão aguda do "eu-lírico" diante do próprio e agudo desconcerto... E assim, a prolixidade do poema português livremente composto por Castilho soa-nos menos pungente e incisiva do que o obtido pela arte catuliana com parcos mas sábios recursos.

Isso não quer dizer, no entanto, que, em si, o texto obtido na língua de chegada não se sustente de maneira alguma enquanto construto poético, tendo em vista o provável intento do tradutor de desviar-se da "insólita" concisão do modelo (pensamos aqui, sobretudo, nas expectativas do público leitor de poesia no século XIX!) para compor, em lugar de dois versos, ao menos duas despretensiosas quadras ${ }^{45}$ em heptassílabos. Ainda,

43 Apropriando-nos, aqui, de um termo cunhado por Haroldo de Campos (HOMERO, 1992. p. 11), usamo-lo com o sentido da busca de formas expressivas, na língua-meta, a aproximar-se da "poeticidade" dos originais mais do que de seus meros referentes [cf. explicação de Antônio Medina Rodrigues in HOMERO, 1992. p. 44: Esta relação entre sentido e referência pode também ser explicitada "fora" da linguagem. Quatro observadores, que olham o mesmo edificio, de pontos diferentes, vêem o mesmo objeto (referência), mas através de quatro imagens (sentidos) distintas. Numa tradução referencial, o que importa é o "edificio" em si mesmo, no caso, o texto original como referência a objetos do mundo físico ou mental. Numa tradução poética, ao contrário, além do referente, deve-se levar em conta as perspectivas de cada tradutor, ou seja, as vivências fenomênicas determinadas pelas obras enquanto matéria, o acontecimento verbal, e as escolhas que o tradutor vai fazendo a partir disso.]. ${ }^{44}$ CITRONI, 1991. p. 179: Nella poesia di Catullo, siamo soliti distinguere gli "epigrammi" in distici (carmi 69-116) dai carmi brevi "polimetrici" (1-60). 45 GOLDSTEIN, 1986. p. 43: Quadrinha é o poema de quatro versos que, geralmente, desenvolve um conceito relativo à filosofia popular. 
do ponto de vista de algum diálogo possível com a arte do original catuliano (embora esse não tenha sido, em absoluto, o aspecto privilegiado pelo tradutor, como dissemos), o caráter popular desse metro $^{46}$ e dessa estrofação na poesia portuguesa estaria a repor algo do "prosaísmo" e "espontaneidade" daquele contexto, no sentido comum do emprego de modos de dizer sem nenhum rebuscamento; e a idêntica antítese a pôr-se nos versos iniciais de ambos os autores, bem como, nos dois derradeiros versos portugueses, a estratégia de aludir à sonoridade do passivo latino excrucior ("sou torturado") pela repetição do adjetivo "cru", indicam alguma atenção de Castilho para com o plano formal do epigrama 85. Nesse último caso, enfim, a adjetivação do poeta português repõe a seu modo a crueza do sofrimento evocado por aquele verbo latino; pois, etimologicamente, ele se vincula de maneira inequívoca à própria palavra crux ("cruz"), designando um suplício amaríssimo e apenas reservado pelos antigos romanos aos não-cidadãos (escravos, estrangeiros...). ${ }^{47}$

\section{d) Conclusão}

Com os exemplos apresentados do trabalho criador desses significativos divulgadores dos antigos em nossa língua, esperamos, através do procedimento prático da leitura comparativa de textos (cotejando originais e suas versões portuguesas), ter oferecido subsídios para que se compreendam as concepções criativas envolvidas a cada vez em que se verteram as obras da literatura clássica. Nesse sentido, julgamos, destacam-se pela qualidade como obras da arte tradutória a ode anacreôntica vertida por Castilho (exemplo de "economia" e fluidez apesar da recorrência a meios expressivos, como vimos, nem sempre muito próximos daqueles presentes no modelo em mira) e, não poderia deixar de ser, o poema número 5 de Catulo, tal como sensivelmente trabalhado por Almeida Garrett.

Os motivos a justificarem essa avaliação, embora peculiares a cada iniciativa criadora, acabam, sintomaticamente, por convergir para um único ponto. Referimo-nos ao fato de que, talvez, correspondendo a iniciativa de traduzir um dado autor ao reconhecimento implícito de suas qualidades poéticas, bem como ao provável intento de "aludir" a elas com

${ }^{46}$ GOLDSTEIN, 1986. p. 27.

${ }^{47}$ HORNBLOWER; SPAWFORTH, 2003. p. 411. 
os recursos característicos da língua de chegada, ambas as realizações citadas conseguiram-no com maior sucesso. Pois, segundo explicamos antes a respeito das traduções anacreônticas, a prolixidade garretiana na porção final do poema prejudicava-lhe não só o rendimento expressivo em si mesmo compreendido, mas a obtenção do que definíramos positivamente no poema grego a orientar-lhe a feitura nos termos da tendência para a límpida "objetividade" dos dizeres; isso, por sinal, permitira-nos desta feita dar a preferência a Castilho, em que pese a alguns poucos pontos menos rendosos em sua versão da ode (caso do comentário "trabalho perdido" em v. 5), como escritor capaz de "substituir" os bons efeitos do original por algo imaterialmente afim no novo (con)texto português.

O caso dos poemas latinos vistos, por outro lado, favoreceu, dadas as opções de tradução adotadas por cada intérprete, observarmos que, se o distanciamento excessivo da letra (e, com ela, do "espírito") dos textos repercutidos resultou em efeitos enfraquecedores do vigor catuliano, o contrário, ou seja, a opção por manter-se próximo da forma em seus aspectos geradores de poeticidade, contribuiu para a rescrita de algo aproximado da força original. Desse modo, Garrett, ao contrário do que ocorrera no exemplo de tradução anterior, viu-se em destaque diante da diluição por Castilho dos sentidos catulianos, tão necessariamente vinculados ao "minimalismo" da forma, ao recompor o poema número 5 com vistas a reconstruir a própria "tessitura" (visual, auditiva, conceitual...) ou, como se quiser "palatabilidade" da parte da obra do lírico romano ecoada...

Assim, em absoluto, sem propô-los como tradutores da mesma ousadia de um Odorico Mendes, esperamos ao menos ter oferecido pontos de apoio analítico para que, em seus melhores momentos, possam dizer-se próximos daquele ideal do intérprete-poeta a alcançar a expressão renovada de significados múltiplos (e não só referentes lógicos) ao verter, logrando, pois, nos termos de Octavio Paz, "com meios diferentes produzir efeitos ou resultados semelhantes". ${ }^{48}$

\footnotetext{
${ }^{48}$ Não tendo podido ter acesso direto à obra em que se encontra (PAZ, Octavio. Claude Lévi-Strauss ou o novo festim de Esopo. Trad. de Sebastião Uchoa Leite: São Paulo, 1993), bem como ao rico prefácio teórico de Paul Valéry à sua afamada tradução francesa das Bucólicas de Virgílio, citamo-lo por via do ensaio de Raimundo Carvalho aludido acima e cientes de que o crítico mexicano, na verdade, partira desse consagrado poeta moderno para posicionar-se como o fez (VIRGÍliO, 2005 a. p. 111).
} 


\section{Referências Bibliográficas}

ACHCAR, Francisco. Lírica e lugar-comum. São Paulo: Edusp, 1994.

ANAKPEONTO $\Sigma$. $\Omega \Delta A I$. Odes de Anacreonte e suas traduções por Almeida Cousin. Rio de Janeiro: Achiamé, 1983.

CAMPOS, Haroldo de. Da tradução como criação e como crítica. In:

Metalinguagem e outras metas. São Paulo: Perspectiva, 1992.

CATULO. O livro de Catulo. Tradução, organização e notas de João A. O. Neto. São Paulo: Edusp, 1996.

CITRONI, Mario. Satira, Epigramma, Favola. In: MONTANARI Franco. (org.). La poesia latina: forme, autori, problemi. Roma: NIS, 1991.

COELHO, José Maria L. Garrett e Castilho. Lisboa: Santos \& Vieira, 1917.

EAGLETON, Terry. Teoria da literatura: uma introdução. Trad. de Waltensir Dutra. São Paulo: Martins Fontes, 2003.

EASTERLING, Peter E.; KNOX, Bernard M. The Cambridge history of classical literature. I- Greek literature. Cambridge: University Press, 1988.

FEDELI, Paolo. Bucolica, Lirica, Elegia. In: MONTANARI, Franco. (org.). La poesia latina: forme, autori, problemi. Roma: NIS, 1990.

FERREIRA, Alberto. Perspectiva do romantismo português. Lisboa: Edições 70, 1971.

FERREIRA, Ermelinda. M. A. Mário de Sá Carneiro e Oscar Wilde: apoteoses. Revista do Centro de Estudos Portugueses, Belo Horizonte, vol. 26, n. 36, p. 252, jul.-dez. 2006.

FONTES Jr., Joaquim B. Eros, tecelão de mitos. São Paulo: Iluminuras, 2003.

GOLDSTEIN, Norma. Versos, sons, ritmos. São Paulo: Ática, 1986.

HOMERO. Odisséia. Tradução de Manuel Odorico Mendes, edição de Antônio Medina Rodrigues. São Paulo: Edusp, 1992.

HORNBLOWER, Simon; SPAWFORTH, Antony. (org.). The Oxford classical dictionary. Oxford: University Press, 2003.

MOISÉS, Massaud. Dicionário de termos literários. São Paulo: Cultrix, 2004.

NERI, Maria Luíza; NOVAK, Maria da Glória (org.). Poesia lírica latina. São Paulo: Martins Fontes, 1992. 
NIETZSCHE, Friedrich. Crepúsculo dos ídolos. Trad. de D. Santos Filho. Lisboa: Guimarães, 1985.

OVIDE. Les amours. Trad. de Henri Bornecque. Paris: Les Belles Lettres, 2003. . Metamorfoses. Trad. de Manuel Maria Barbosa du Bocage, ed. de João Angelo Oliva Neto. São Paulo: Hedra, 2007.

ROSENMEYER, Patricia A. The poetics of imitation: Anacreon and the anacreontic tradition. Cambridge: University Press, 1992.

SPALDING, Tassilo. O. Dicionário da mitologia greco-latina. Belo Horizonte: Itatiaia, 1965.

VARRON. Économie rurale. Texte établi, traduit et commenté par J. Heurgon. Paris: "Les Belles Lettres", 2003.

VEYNE, Paul (org.). História da vida privada: I do Império Romano ao ano 1000. Trad. de Hildegard Feist. São Paulo: Companhia das Letras, 1993.

VIRGÍliO. Bucólicas. Tradução e comentário de Raimundo Carvalho. Belo Horizonte: Crisálida, 2005 a.

Eneida. Trad. de Manuel Odorico Mendes, ed. de Antônio Medina Rodrigues. São Paulo: Ateliê Editorial/ UNICAMP, 2005 b.

\section{Resumo}

Estudamos aqui o processo de tradução de dois poemas de Catulo e uma ode anacreôntica por Antônio Feliciano de Castilho e Almeida Garrett pela comparação de originais com suas versões portuguesas. Intenta-se, assim, mostrar o lado criativo dos tradutores e propô-los mais ou menos bem sucedidos ao aproximar-se ou afastar-se poeticamente das belezas dos textos grego e latino que trabalharam.

\section{Résumé}

Nous étudions ici les procédés de traduction de deux poèmes de Catulle et d'une ode anacréontique par Antonio Feliciano de Castilho et Almeida Garrett par la comparaison des originaux avec ses versions portugaises. On essaye, de cette façon là, de montrer le coté créatif des traducteurs et de proposer une réussite plus ou moins complète selon leur proximité ou éloignement des beautés poétiques des textes grec et latin qu'ils ont travaillés. 